\title{
Saline Water Desalination with Single-pass Ion-exchange Membrane Electrodialysis - Computer Simulation
}

\section{Yoshinobu Tanaka}

IEM Research, 1-46-3 Kamiya, Ushiku-shi, Ibaraki 300-1216, Japan

\section{Abstract}

\section{Publication History:}

A computer simulation program of ion-exchange membrane electrodialysis is developed for saline water desalination. Inputting the specifications of an electrodialyzer and operating conditions into the program, the following performance of the electrodialyzer is computed. Ion flux and solution flux across a membrane pair; Energy consumption; Salt concentration at the outlets of desalting and concentrating cells; Desalting ratio; Water recovery; Current efficiency; Limiting current density; Current density distribution; Electric resistance of desalting and concentrating solutions and a membrane pair; Electric current leakage; Pressure drop. Constant voltage mode single-pass electrodialysis program is written in the Excel spread sheet and it is integrated in the website. The program in the website can be operated easily with trial-and-error calculation.

\section{Introduction}

An electrodialysis (ED) processes is applied widely for saline water desalination. The ED processes are classified to a singlepass (continuous) process, a feed-and-bleed process and a batch process. Among these processes, the single-pass process is the most fundamental one, and the performance of the process is discussed from various points as follows.

Belfort and Daly [1] constructed optimization routine for a singlepass electrodialysis plant. The algorithm was applied to the Office of Saline Water test bed plant at Webster, South Dakota and compared the actual cost and operating conditions. Avriel and Zeligher [2] developed a mathematical model for preliminary engineering design and economical evaluation of a single-pass ED plant. Detailed cost computations were performed resulting in capital investment and annual operating costs. Lee et al. [3] developed a computer simulation program for describing a single-pass process and estimated investment and operation costs. Further, ED plant was designed and optimized in terms of overall costs and the different parameters. Moon et al. [4] investigated ionic transport across membranes based on the one- and two-dimensional single-pass ED modeling using the principles of electrochemistry, transport phenomena and thermodynamics. Fidaleo and Moresi [5] simulated mass transfer, mass balance, potential drop and limiting current density in a single-pass operation based on the Nernst-Planck equation. Sadrzadeh et al. [6] modeled continuous flow desalination starting from a differential equation of steady-state mass balance and gives salt concentration in dilute compartments or separation percent for various voltages, flow rates and feed concentrations. Nikonenko et al. [7] described ED or electrodeionization characteristics (mass transfer coefficient, Sherwood number, degree of desalination and others). The reasonability of the functions was discussed with experimental measurements. Brauns et al. [8] developed a simulation model through solver software. Experimental verification of the software was performed using an industrial type pilot plant. Limiting current density was theoretically evaluated in the model calculations for design purposes and corrected with the experimental results.

The single-pass program becomes the basis of the feed-and-bleed program [9] and the batch program [10]. This is because the singlepass program describes the function of the electrodialyzer. This article describes the single-pass program established based on the principles of electrochemistry and ED experiments being supplied strong electrolyte solutions [11]. Calculation is carried out in the spread sheet with a use of common software (Excel) and ordinary hardware (Computer). The program is integrated in websites. So, readers can operate the program in the websites (Attached section) by inputting the source codes i.e. optional process specifications and operating conditions. The program aims to function as a pilot plant operation.

\section{Single-pass ED Process}

The one-stage single-pass (continuous) ED process is illustrated in Figure 1. The electrodialyzer is incorporated with desalting cells, concentrating cells in the stack marked with gray. Number of cells is $N$ for desalting cells and $N+1$ for concentrating cells. The anode and cathode cells are placed at both outsides of the stack and an electric current is supplied between the electrodes. A feeding solution of salt concentration $C^{\prime}$ in is supplied to desalting cells at linear velocity of $u_{\text {in }}^{\prime}$ at the inlets. $C_{\text {in }}^{\prime}$ and $u_{\text {in }}^{\prime}$ are decreased to respectively $C_{\text {out }}^{\prime}$ and $u_{\text {out }}^{\text {' }}$ at the outlets of desalting cells. A part of the feeding solution is also supplied to concentrating cells for preventing scale formation in the concentrating cells. The salt concentration and linear velocity in concentrating cells are respectively $C_{i n}^{\prime}=C_{i n}^{\prime}$ and $u^{\prime \prime}{ }_{i n}$ at the inlets and $C{ }^{\prime \prime}{ }_{\text {out }}$ and $u^{\prime \prime}{ }_{\text {out }}$ at the outlets. Partition cells are incorporated between the stack and electrode cells for preventing the influence of electrode reactions to the performance of the electrodialyzer. A part of a concentrated solution flowing out from the outlets of concentrating cells is supplied to electrode cells and partition cells. A multi-stage ED process is formed by arranging the single-pass process in Figure 1 in series.

\section{Mass Transport in the Single-pass Process}

Figure 2 illustrates the mass transport in the single-pass (continuous) process. A salt solution (raw salt solution, concentration: $C_{\text {in }}^{\prime}$ ) is supplied to the inlets of desalting cells (De) at average linear velocity

"Corresponding Author: Dr. Yoshinobu Tanaka, IEM Research, 1-46-3 Kamiya, Ushiku-shi, Ibaraki 300-1216, Japan, Tel: +81-29-874-5400; E-mail: fwis1202@mb.infoweb.ne.jp

Citation: Tanaka Y (2016) Saline Water Desalination with Single-pass Ionexchange Membrane Electrodialysis - Computer Simulation. Int J Comput Softw Eng 1: 101. doi: http://dx.doi.org/10.15344/ijcse/2016/101

Copyright: () 2016 Tanaka. This is an open-access article distributed under the terms of the Creative Commons Attribution License, which permits unrestricted use, distribution, and reproduction in any medium, provided the original author and source are credited. 


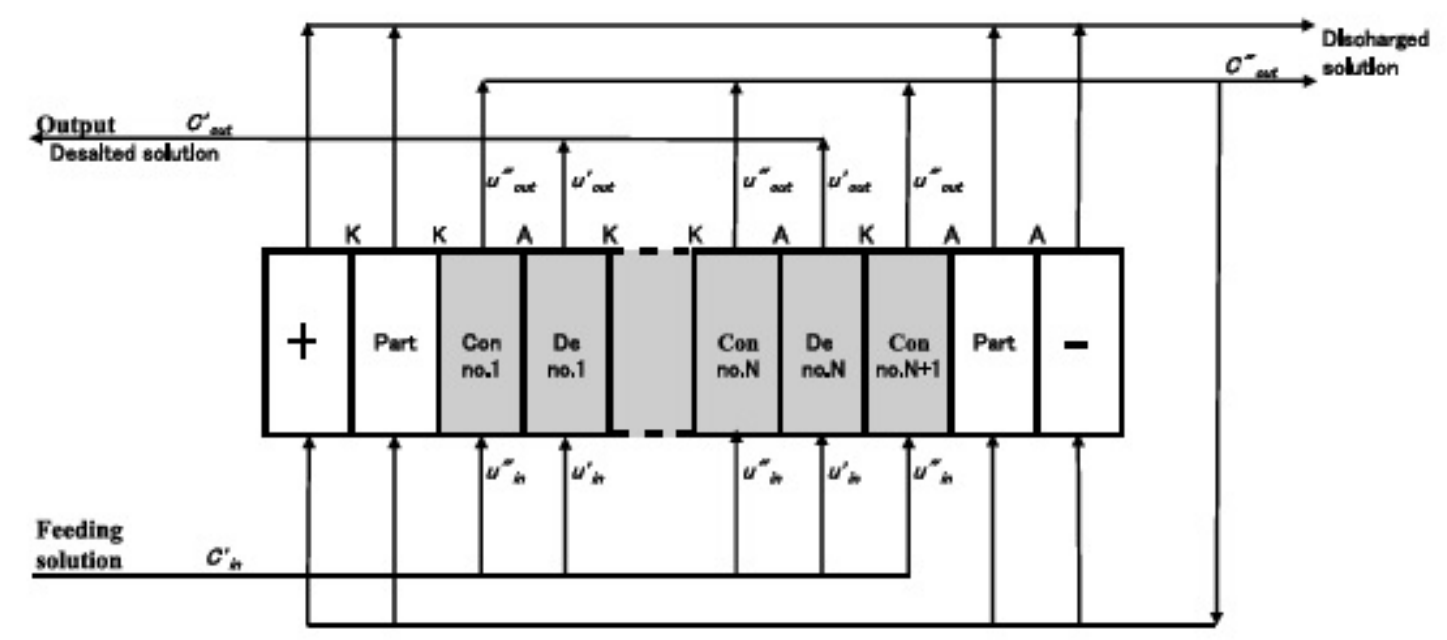

$\mathrm{K}$; Cation exchange membrane A; Anion exchange membrane + ; Anode

$-;$ Cathode
De ; Desalting cell

Con ; Concentrating cell

Part ; Partition cell

Figure 1: Single-pass (continuous) electrodialysis process. Tanaka, 2012, p. 17, Figure 3.

of $u_{i n}$. For preventing scale formation in concentrating cells, a part of a raw salt solution is supplied also to the inlets of concentrating cells (Con) at the average linear velocity of $u^{\prime \prime}$. By supplying an electric current $I$, ions and solutions are transferred from desalting cells to concentrating cells across an ion exchange membrane pair and their flux is defined by $J_{S}$ and $J_{V}$ respectively. In desalting (concentrating) cells, salt concentration is decreased (increased) along the flowpass from $C_{i n}^{\prime}\left(C^{\prime \prime}{ }_{i n}=C_{i n}^{\prime}\right)$ under applied average current density $I / S$ and reaches average salt concentration $C_{\text {out }}^{\prime}\left(C^{\prime \prime}{ }_{\text {out }}\right)$ at the outlets of desalting (concentrating) cells. Salt concentration change in desalting cells causes current density change along the flow-pass from $i_{i n}$ at the inlets to $i_{\text {out }}$ at the outlets. The current density becomes $j$ at $x$ distant from the inlets of desalting cells. $I / S, J_{S}, J_{v}, C_{p}^{\prime}, C^{\prime \prime}, u_{p}^{\prime}$ and $u^{\prime \prime}$ are altogether the values at $x=p l$ distant from the inlets of desalting and concentrating cells. $V_{i n}, V_{\text {out }}$ and $\mathrm{V}_{\mathrm{p}}$ are voltage difference between electrodes respectively at the inlets $(x=0)$, the outlets $(x=l)$ and $\mathrm{x}=$ $p l$ of desalting cells $\left(V_{\text {in }}=V_{\text {out }}=V_{p}\right)$.

Figure 3 illustrates the desalting cell and concentrating cell.

\section{Specifications and Operating Conditions of an Electrodialyzer}

(1) Flow-pass thickness in a desalting and a concentrating cell; $a(\mathrm{~cm})$

(2) Flow-pass width in a desalting and a concentrating cell; $b(\mathrm{~cm})$

(3) Flow-pass length in a desalting and a concentrating cell; $l(\mathrm{~cm})$

(4) Membrane area; $S=b l\left(\mathrm{~cm}^{2}\right)$

(4) Number of stacks in an electrodialyzer; 1

(5) Number of desalting cells, concentrating cells and membrane pairs integrated in a stack; $N, N+1, N$

(6) Probe electrodes are inserted into concentrating cells integrated at the ends of a stack for measuring cell voltage

(7) Average current density; $I / S\left(\mathrm{~A} / \mathrm{cm}^{2}\right)$

(8) Salt concentration at the inlets of desalting cells; $C_{i n}{ }_{i n}\left(\mathrm{eq} / \mathrm{cm}^{3}\right)$

(9) Salt concentration at the inlets of concentrating cells; $C_{i n}^{\prime}=C_{i n}^{\prime}$ $\left(\mathrm{eq} / \mathrm{cm}^{3}\right)$

Int J Comput Softw Eng
(10) Linear velocity at the inlets of desalting and concentrating cells; $u_{i n}^{\prime}, u^{\prime \prime}{ }_{i n}(\mathrm{~cm} / \mathrm{s})$

(11) Standard deviation of the normal distribution of solution velocity ratio; $\sigma$

(12) Flow system in desalting and concentrating cells; single-pass flow

(13) Diagonal net spacers are integrated in desalting and concentrating cells and in desalting and concentrating slots. Dimensions of a spacer are:

Diameter of a spacer rod $d_{s}=$ half thickness of the cell; $a / 2$

Distance between the rods; $\chi$

Crossing angle of the rods; $\theta$

(14) Number and dimension of the cells and slots in a cell pair are:

Number thickness width length

Desalting cell

Concentrating cell

Desalting slot and duct

Concentrating slot and duct

$\begin{array}{llll}1 & a & b & l \\ 1 & a & b & l \\ n^{\prime} & a & w^{\prime} & h^{\prime} \\ n^{\prime \prime} & a & w^{\prime \prime} & h^{\prime \prime}\end{array}$

\section{Electrodialysis Program}

Computing processes are explained definitely in the book "Ion Exchange Membranes. Fundamentals and Applications 2nd edition" [12]. This section summarizes the specifications of the program briefly.

\subsection{Overall mass transport equation}

Fluxes of ions $J_{S}$ and a solution $J_{V}$ across an ion exchange membrane pair at $x=p l$ distant from the inlets of desalting and concentrating cells are expressed by the following overall mass transport equation [13].

$J_{S}=\lambda(I / S)-\mu\left(C_{p}{ }_{p}-C_{p}^{\prime}\right)=\left(t_{K}+t_{A}-1\right)(I / S) / F-\mu\left(C_{p}^{\prime \prime}-C_{p}^{\prime}\right)=\eta(I / S) / F$

$J_{V}=\varphi(I / S)+\rho\left(C_{p}^{\prime \prime}-C_{p}^{\prime}\right)$ 
Citation: Tanaka Y (2016) Saline Water Desalination with Single-pass Ion-exchange Membrane Electrodialysis - Computer Simulation. Int J Comput Softw Eng 1: 101. doi: http://dx.doi.org/10.15344/ijcse/2016/101

Page 3 of 10

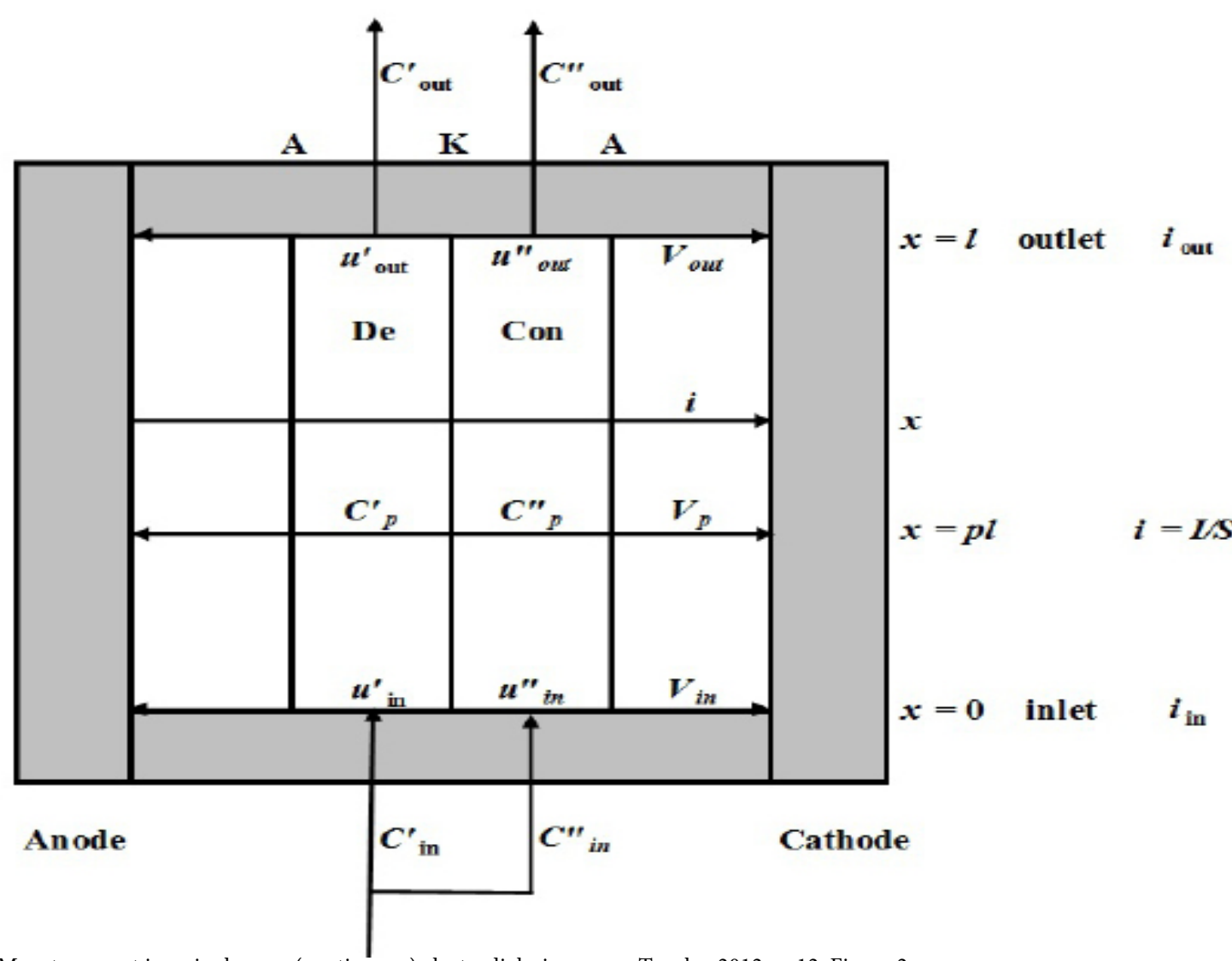

Figure 2: Mass transport in a single-pass (continuous) electrodialysis process.Tanaka, 2012, p. 12, Figure 2.

De: Desalting cell, Con: Concentrating cell, K: Cation exchange membrane, A: Anion exchange membrane

in which $\lambda\left(e q C^{-1}\right)$ is the overall transport number, $\mu\left(\mathrm{cm} \mathrm{s}^{-1}\right)$ is the overall solute permeability, $\varphi\left(\mathrm{cm}^{3} \mathrm{C}^{-1}\right)$ is the overall electro-osmotic permeability and $\rho\left(\mathrm{cm}^{4} \mathrm{eq}^{-1} \mathrm{~s}^{-1}\right)$ is the overall volume osmotic permeability. $t$ is the transport number of counter-ions in the membrane. $\eta$ is the current efficiency and $F$ is the Faraday constant.

$\rho$ versus $\lambda, \mu$ and $\varphi$ plots are given by the following empirical equations.

$\lambda=9.208 \times 10^{-6}+1.914 \times 10^{-5} \rho$

$\mu=2.005 \times 10^{-4} \rho$

$\varphi=3.768 \times 10^{-3} \rho^{0.2}-1.019 \times 10^{-2} \rho$

$\rho$ versus alternating current electric resistance of an ion-exchange membrane pair $r_{\text {alter }}=r_{\text {alter } \mathrm{K}}+\mathrm{r}_{\text {alter, } \mathrm{A}}$ is expressed by the following equation [14].

$r_{\text {alter }}=r_{\text {alter }{ }^{\prime} \mathrm{K}}+r_{\text {alter }, \mathrm{A}}=1.2323 \rho^{-(1 / 3)}$

The relationship between $\rho$ and solution temperature $T\left({ }^{\circ} \mathrm{C}\right)$ is approximated by the following equation [15].

$\rho=3.421 \times 10^{-3}+3.333 \times 10^{-4} T$

Eqs. (3) - (6) mean that $\rho$ is the leading parameter and it represents all of the overall membrane characteristics. $\lambda, \mu, \varphi, r_{\text {alter } K}+r_{\text {atler, } A}$ and $\rho$ are determined by setting T in Eq. (7). Eqs. (3) - (7) are empirical equations developed using electrodialyzers integrated with commercially available homogeneous ion- exchange membranes and supplying inorganic strong electrolyte solutions. The equations are practically applicable under the above situations.

Membrane pair alternating electric resistance ralter is calculated using the following equations [14].

$r_{\text {alter }}=1.2323 \rho^{-1 / 3}$

Ion-exchange membranes usually work under a direct electric current. The direct current electric resistance of the membrane $r_{\text {dire }}$ $=r_{\text {memb }}$ is influenced by the salt concentration of the solutions placed on both sides of the membrane, and it is expressed by the following equation [16].

$r_{\text {dire }}=\left(\frac{r_{\text {dire }}^{*}}{r_{\text {alter }}}\right) \times\left(\frac{r_{\text {dire }}}{r_{\text {dire }}^{*}}\right) \times r_{\text {alter }}=r_{\text {memb }}$

where

$\log \left(\frac{r_{\text {dire }}^{*}}{r_{\text {alter }}}\right)=0.3380+0.6386 \log k^{\prime}+0.2961\left(\log k^{\prime}\right)^{2}$

$\frac{r_{\text {dire }}}{r_{\text {dire }}^{*}}=1.000-0.1359 \log \left(\frac{k^{\prime \prime}}{k^{\prime}}\right)$

$\kappa^{\prime}$ and $\kappa^{\prime \prime}$ are the specific conductivity of the solutions in a desalting cell and a concentrating cell respectively.

\subsection{Feeding solution}

Feeding solutions are limited to strong electrolyte solutions such 
Citation: Tanaka Y (2016) Saline Water Desalination with Single-pass Ion-exchange Membrane Electrodialysis - Computer Simulation. Int J Comput Softw Eng 1: 101. doi: http://dx.doi.org/10.15344/ijcse/2016/101

Page 4 of 10

as seawater, diluted seawater, concentrated seawater etc. Physical properties such as density, viscosity, specific conductivity, activity coefficient of the solution are expressed by the functions of electrolyte concentrations and temperature.

\subsection{Salt concentration and linear velocity in desalting cells}

Salt concentration and linear velocity at the inlets of the cells are set up freely. The solution velocity ratio $\xi$ in desalting cells integrated in a stack in an electrodialyzer is defined by Eq. (12):

$$
\xi=\frac{u^{*}-\bar{u}}{\bar{u}}
$$

where $u^{*}$ is the linear velocity in every desalting cell and $\bar{u}$ is the average linear velocity in a stack. The frequency distribution of $\xi$ is expressed by the normal distribution. Thus the minimum of $\xi$ and $u^{*}$ is equated with $-3 \sigma$ and $u$, respectively, where $\sigma$ is the standard deviation of the normal distribution of $\xi$ and $\mathrm{u}$ is the minimum value of linear velocities within all desalting cells in a stack. Putting $\xi=-3 \sigma$ and $u^{*}=u$ in Eq. (12) yields Eq. (13):

$$
u=u(1-3 \sigma)
$$

$\sigma=0.1$ is assumed in the program taking into account the experimental results. $\sigma$ affects on the limiting current density and functions as a safety parameter to operate an electrodialyzer. $\sigma$ does not exert an influence to the performance of an electrodialyzer excepting the limiting current density.

\subsection{Current density distribution}

In an ED system, current density is decreased due to the salt concentration decrease in desalting cells along a flow-pass. This phenomenon have a effect on the limiting current density of an electrodialyzer $(I / S)_{l i m}$. The current density distribution is assumed to be approximated by the following quadratic equation expressed at $x / l$ distant from the inlet of a desalting cell.

$$
i=a_{1}+a_{2}\left(\frac{x}{l}\right)+a_{3}\left(\frac{x}{l}\right)^{2}
$$

To determine $a_{1}, a_{2}$ and $a_{3}$ in Eq. (14), three simultaneous equations are set up $[17,18]$ (Tanaka, 2000, 2002) assuming voltage differences between electrodes are constant and independent of $x / l$.

\subsection{Limiting current density}

When current density reaches the limit of a cation-exchange membrane $i_{\text {lim }}$ at the outlet of a desalting cell in which linear velocity becomes the least among $u_{i n}^{\prime} ; u_{i n}^{\prime}$, the average current density applied to an electrodialyzer is defined as its limiting current density $(I / S)_{\lim }$ which is expressed by Eq. (15).

$\left(\frac{I}{S}\right)_{\lim }=\left\{l_{1}+l_{2}\left(\frac{T}{25}\right)+l_{3}\left(\frac{T}{25}\right)^{2}\right\} \frac{m_{1}+m_{2} u_{\text {in }}^{\prime \prime \prime}}{\zeta_{\text {out }}}\left(C_{\text {out }}^{\text {"\# }}\right)^{n_{1}+n_{2} u_{\text {in }}^{\prime \prime \prime}}$

in which, $C_{\text {out }}^{\prime \text { " }}$ is $C_{\text {out }}^{\prime}$ at $u^{\prime}=u_{\text {in }}^{\prime \prime}$ which is given by:

$u_{\text {in }}^{\prime \#}=u_{i n}^{\prime}(1-3 \sigma)$

$\sigma$ is the standard deviation of the normal distribution of solution velocity ratio $\xi$, and it is defined in Eq. (13)

\subsection{Salt concentration and linear velocity in concentrating cells}

Salt concentration and linear velocity at the inlets of concentrating cells are set up freely and those at the other positions $(0<\mathrm{x} / \mathrm{l}<1)$ are calculated from the material balance.

\subsection{Electric resistance of a desalting and a concentrating cell}

Electric resistance of a desalting cell $r$ ' and of a concentrating cell $r$ " in an electrodialyzer are given as:

$$
\begin{aligned}
& r^{\prime}=\frac{a}{(1-\mathrm{a}) k^{\prime}} \\
& r^{\prime \prime}=\frac{a}{(1-\mathrm{a}) \kappa^{\prime \prime}}
\end{aligned}
$$

$\varepsilon$ defines an electric current screening effect of a diagonal net spacer and it is determined by the volume ratio of spacer rods in a desalting and concentrating cell as follows.

$$
\varepsilon=\frac{\pi a}{8 \chi \sin \theta}
$$

in which $\chi$ is the distance between spacer rods, $\theta$ is the crossing angle of the rods.

\subsection{Cell voltage, energy consumption, water recovery and desalting ratio}

Ohmic voltage and membrane voltage at the inlet of the desalting cell $\left(V_{\Omega, i n}\right.$ and $\left.V_{\text {membin }}\right)$ and those at the outlet of the desalting cell $\left(V_{\Omega, \text { out }}\right.$ and $\left.V_{\text {membout }}\right)$ are:

$V_{\Omega, \text { in }}=\left(r_{\text {in }}^{\prime}+r_{\text {memb,in }}+r^{\prime \prime}\right) i_{\text {in }}$

$V_{m e m b, i n}=2\left(t_{K}+t_{A}-1\right) \times\left(\frac{R T}{F}\right) \ln \frac{Y^{\prime \prime}{ }_{i n} C_{i n}^{\prime \prime}}{Y^{\prime}{ }_{i n} C^{\prime}{ }_{i n}}$

$V_{\dot{\mathrm{U}}, \text { out }}=\left(\sum_{j=0}^{n} Y_{j} r_{\text {out }, j}^{\prime}+\sum_{j=0}^{n} Y_{j} r_{\text {memb }, \text { out }, j}+r_{\text {out }}^{\prime \prime} N\right) \times i_{\text {out }} \times\left(\frac{1}{N}\right)$

$V_{\text {memb }, \text { out }}=2\left(t_{K}+t_{A}-1\right)\left(\frac{R T}{F}\right) \sum_{j=0}^{n} \ln \frac{\gamma_{\text {out }}^{\prime \prime} C_{\text {out }}^{\prime \prime}}{\gamma_{\text {out }, j}^{\prime} C_{\text {out }, j}^{\prime}} \times\left(\frac{1}{N}\right)$

in which, $j$ stands for group $j$ in the normal distribution.

Cell voltage $V_{\text {cell }}$ is introduced from Eqs. (21) - (23) as shown in Figure (24).

$V_{\text {cell }}(\mathrm{V} /$ pair $)=V_{\Omega, \text { in }}+V_{\text {memb,in }}=V_{\Omega, \text { out }}+V_{\text {memb,out }}$

Energy consumption $E$ is expressed by the following equation.

$E\left(k W h / m^{3}\right)=\frac{V_{\text {cell }} I}{q_{\text {out }}^{\prime}} \times 3600 \times 10^{3}$

$q_{\text {out }}^{\prime}$ is the solution volume; output of the desalted solution $\left(\mathrm{cm}^{3} / \mathrm{s}\right.$ cell).

Water recovery $R e$ is:

$\alpha=\left(1-\frac{C_{\text {out }}^{\prime}}{C_{\text {out }}^{\prime}}\right)$

Desalting,ratio $\alpha$ is:

$\operatorname{Re}=\frac{q_{\text {out }}}{q_{\text {in }}^{\prime}+q_{\text {in }}^{\prime \prime}}$

5.9 Pressure drop in desalting and concentrating cells and slots

Hydrodynamic diameter of a desalting or a concentrating cell (electric current passing section); $d_{H, c e l l}$ and that of a desalting or a concentrating slot; $d_{H, s l o t}$ incorporated with a diagonal net spacer are expressed by the following equation $[19,20]$.

$d_{H, c e l l}=\frac{8-\pi \frac{a}{\chi}}{4\left(\frac{1}{b}+\frac{1}{a}\right)+2 \pi\left(1-\frac{a}{4 b}\right) \frac{1}{\chi}}$

$d_{H, s l o t}=\frac{8-\pi \frac{a}{\chi}}{4\left(\frac{1}{w}+\frac{1}{a}\right)+2 \pi\left(1-\frac{a}{4 w}\right) \frac{1}{\chi}}$

in which $w$ is the flow-pass width in the slot (Figure 3). 
Citation: Tanaka Y (2016) Saline Water Desalination with Single-pass Ion-exchange Membrane Electrodialysis - Computer Simulation. Int J Comput Softw Eng 1: 101. doi: http://dx.doi.org/10.15344/ijcse/2016/101

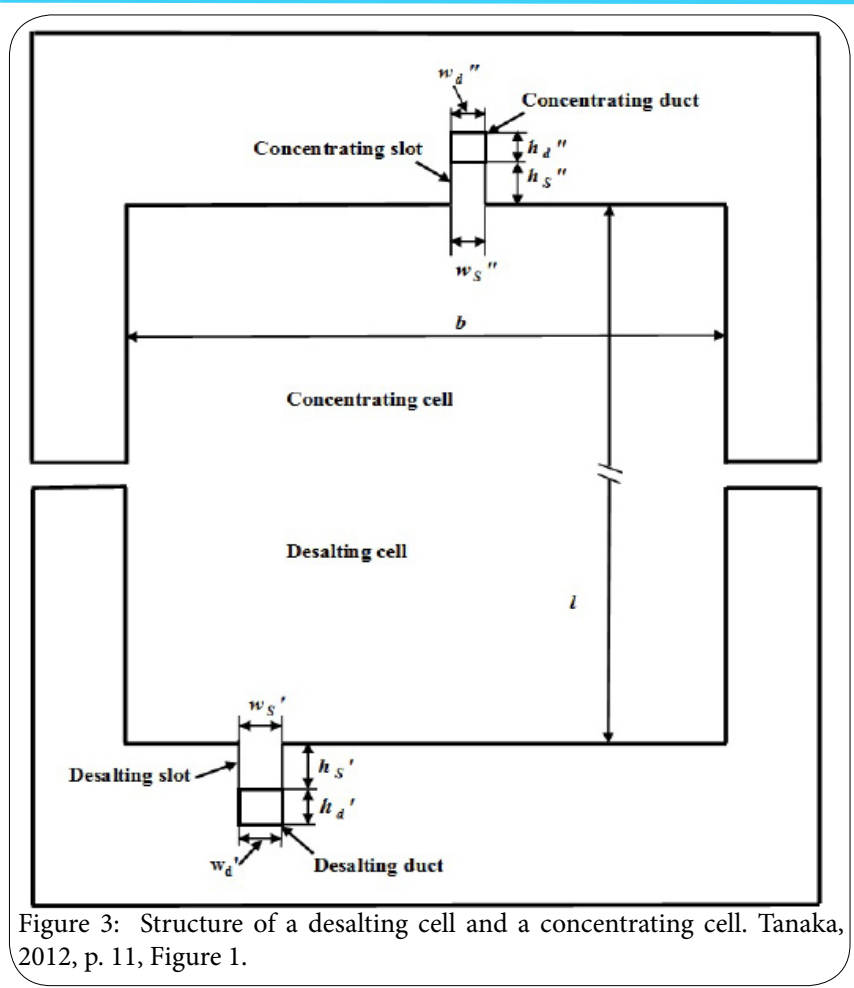

Pressure difference between the inlet and the outlet of the cell in a desalting or a concentrating cell; pressure drop in the cell (in the electric current passing section) $\Delta P_{c e l l}$ and that in a desalting or a concentrating slot; pressure drop in the slot $\Delta P_{\text {slot }}$ are [20].

$$
\begin{aligned}
& \Delta P_{\text {cell }}(p a)=\frac{3.2 \mu l u_{\text {cell }}}{\left(d_{H, c e l l}\right)^{2}} \\
& \Delta P_{\text {slot }}(p a)=\frac{3.2 \mu \mathrm{h} u_{\text {cell }}}{\left(d_{H, c e l l}\right)^{2}}
\end{aligned}
$$

in which, $h$ is the flow-pass length in the slot (Figure 3 ), $u_{\text {cell }}$ is linear velocity in the desalting or concentrating cell, $u_{\text {slot }}$ is linear velocity in the slot. $\mu\left(\mathrm{g} \mathrm{cm}^{-1} \mathrm{~s}^{-1}\right)$ is the viscosity coefficient of a solution. $u_{\text {cell }}$ and $u_{\text {slot }}$ are linear velocity in the cell and slot. $\Delta P(\mathrm{~m})$ is calculated using $\Delta P(\mathrm{~m})=1.01972 \times 10^{-4} \Delta P(\mathrm{~Pa})$

\subsection{Elecric current leakage}

In an electrodialyzer, a part of an electric current does not pass through ion-exchange membranes and it flows between electrodes through slots and ducts. Electric current leakage is an ineffective and inevitable phenomenon which increases energy consumption in an ED process. Leakage current ratio $I_{L} / I_{0}$ is introduced by Wilson [21] $\frac{I_{L}}{I_{0}}=\frac{\sum_{n=1}^{N / 2} n^{2}}{(N / 2)\left\{R_{S}^{*}+\left(1+R_{d}^{*}\right) \sum_{n=1}^{N / 2} n\right\}}=\frac{2(N+1)(N+2)}{24 R_{S}^{*}+3\left(1+R_{d}^{*}\right) N(N+2)}$

where $R_{s}^{*}$ is the overall slot electric resistance and $R_{d}{ }^{*}$ is the overall duct electric resistance defined as follows.

$$
\begin{aligned}
& R_{S}^{*}=\frac{R_{s}}{R} \\
& R_{d}^{*}=\frac{R_{d}}{R}
\end{aligned}
$$

in which $R$ is the electric resistance of a cell pair and

$$
\frac{1}{R_{s}}=\left(\frac{1}{R_{s, \text { in }}^{\prime}}+\frac{1}{R_{s, \text { out }}^{\prime}}\right)+\left(\frac{1}{R_{s, \text { in }}^{\prime \prime}}+\frac{1}{R_{s, \text { out }}}\right)
$$

$$
\frac{1}{R_{d}}=\left(\frac{1}{R_{d, \text { in }}^{\prime}}+\frac{1}{R_{d, \text { out }}^{\prime}}\right)+\left(\frac{1}{R_{d, \text { in }}^{\prime \prime}}+\frac{1}{R_{d, \text { out }}^{\prime \prime}}\right)
$$

5.11 Structure of a desalting cell, concentrating cell, slot and duct and cell pair number.

The following parameters are set up freely.

Thickness $a$, width $b$ and length $l$ of a desalting and a concentrating cell; Cell pair number $N$;

Structure of a diagonal net spacer, a slot and a duct.

\subsection{Units in the program}

The program consists of empirical equations and principles of electrochemistry. It is developed fundamentally based on the SI units with prefixes. In order to apply the program to industrial operation, the units are suitably converted to industrial units such as $\mathrm{kWh} / \mathrm{m}^{3}$, $\mathrm{m}^{3} / \mathrm{h}, \mathrm{A} / \mathrm{dm}^{2}, \mathrm{mg} / \mathrm{dm}^{3}=\mathrm{ppm}$ etc. Thus the units are substantially mixed and not unified.

\section{Program}

The program is developed based on fundamentally the equations described in Section 5. The single-pass ED process is classified as follows.

(1)Constant current single-pass process

(2)Constant voltage single-pass process

(3)Constant salt concentration single-pass process

Among the above processes, the constant voltage single-pass process is widely applied because the ED operation is carried out stably. Fig 4 shows the constant voltage single-pass program. The computation is carried out through three steps.

(1) Step 1 (Computer operation time; 5 min)

Decision point 1 (Red)

$I^{*}$ (Control key 1$)$ is adjusted to equalize $V_{\text {celli }}^{\text {pput }}$ with computed $V_{\text {cell }}$ as follows.

$V_{\text {cell }}^{\text {input }}=V_{\text {cell }}$

Decision point 2 (Blue)

$C_{p}^{\prime *}$ and $C_{p}{ }_{p}^{*}$ (Control key 2) are equalized to computed $C_{p}$ and $C_{p}{ }_{p}$ for preventing circulation reference as follows

$C_{p}^{*}=C_{p}^{\prime} C^{\prime \prime} p^{*}=C_{p}^{\prime \prime}$

Decision point 3 (Purple)

$p^{*}$ (Control key 3$)$ is adjusted to realize

$\zeta_{\text {inout }}=\zeta_{\text {inp }}$

(2) Step 2 (Computer operation time; $2 \mathrm{~min}$ )

Decision point 4 (Orange)

$I^{\#^{*}}$ (Control key 4$)$ is adjusted to realize

$I^{\#^{*}}\left(1-I_{L} / I^{* *}\right)=I$

(3) Step 3 (Computer operation time; $2 \mathrm{~min}$ ) 
Citation: Tanaka Y (2016) Saline Water Desalination with Single-pass Ion-exchange Membrane Electrodialysis - Computer Simulation. Int J Comput Softw Eng

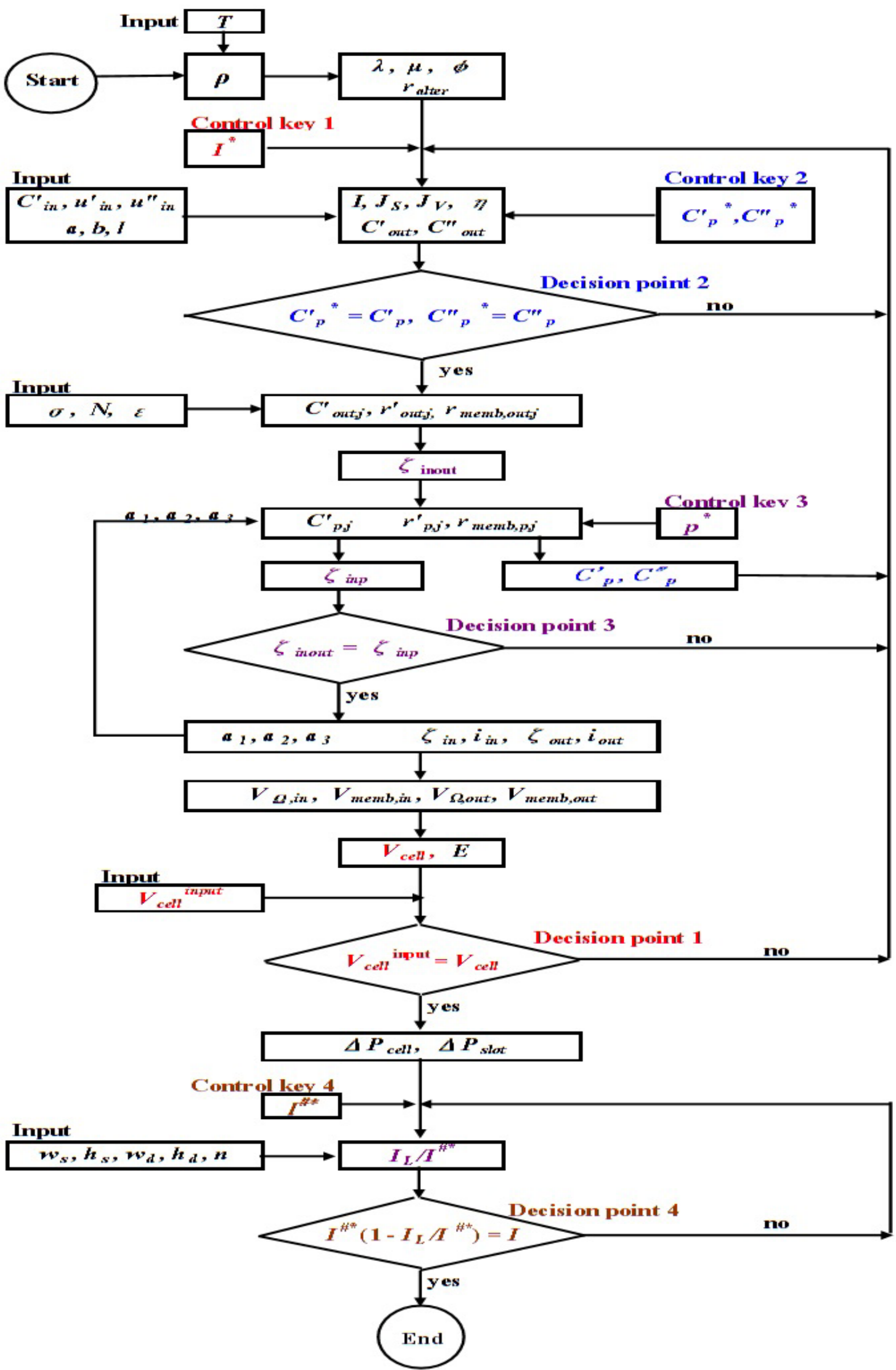

Figure 4: Constant voltage single-pass (continuous) electrodialysis program chart. 
Citation: Tanaka Y (2016) Saline Water Desalination with Single-pass Ion-exchange Membrane Electrodialysis - Computer Simulation. Int J Comput Softw Eng 1: 101. doi: http://dx.doi.org/10.15344/ijcse/2016/101

Page 7 of 10

In the limiting current density program (Figure 5), control key $\mathrm{C}^{\prime}$ is adjusted to realize

$Z_{1}=Z_{2}$

where $C_{\text {out }}^{\#^{*}}$ is $C_{\text {out }}^{\prime}$ at $u_{\text {in }}^{\prime}=u_{\text {in }}^{\prime *}$ given by Eq. (16).

\section{Results}

Ion flux $J_{S}$ and solution flux $J_{V}$ are plotted against $V_{\text {cell }}$ (Figure 6). Current density $I / S$ and energy consumption $E$ are plotted against $V_{\text {cell }}$ (Figure 7). I (A) is the total electric current and $\mathrm{S}\left(\mathrm{cm}^{2}\right)$ is the effective membrane area, thus $I / S$ is the average current density. Fig. 8 shows the salt concentration at the outlets of desalting cell $C_{\text {out }}^{\prime}$

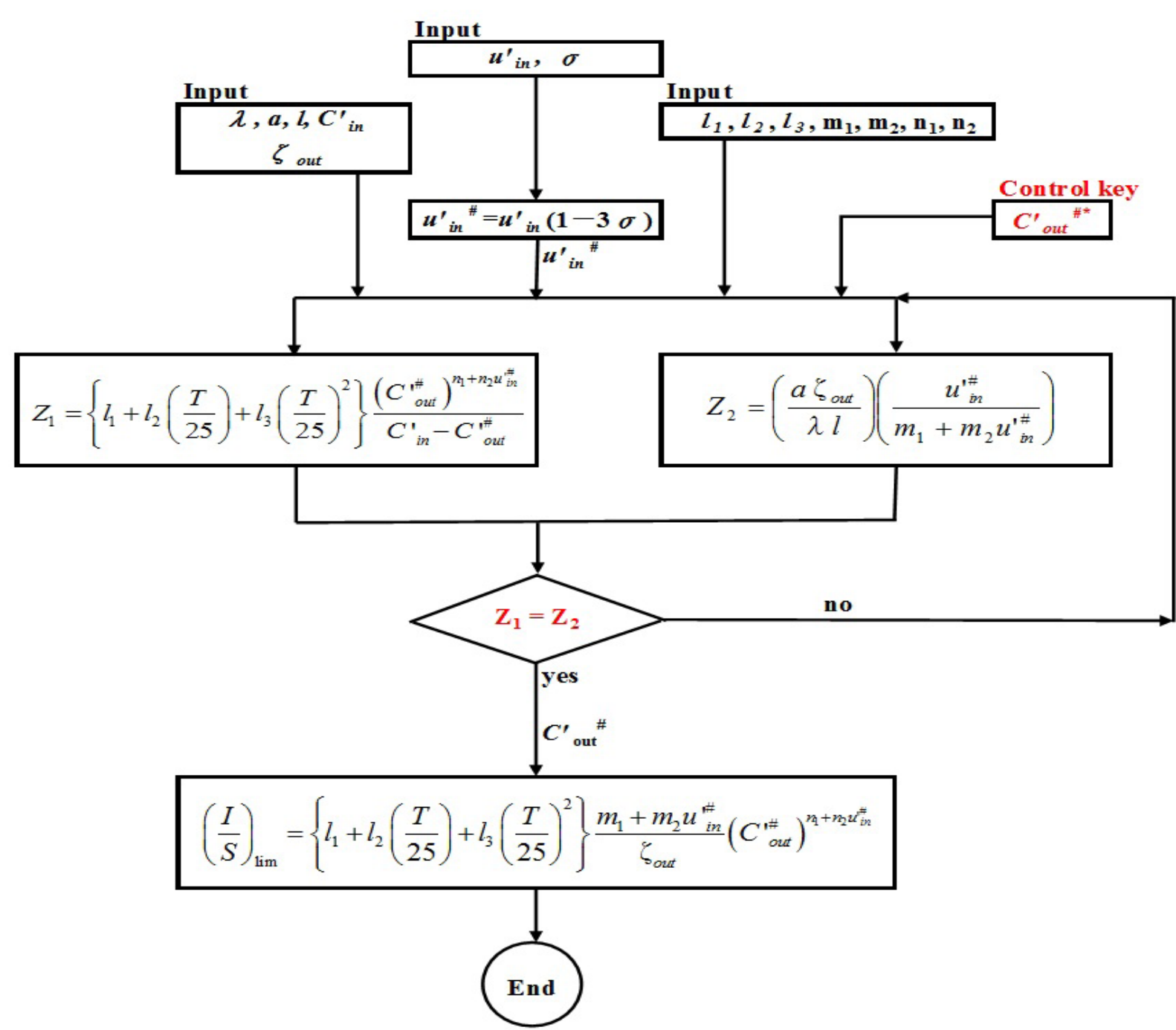

Figure 5: Limiting current density program chart. " means the least value in an electrodialyzer. Tanaka, 2012, p. 19 , Figure 6.

\section{Computation}

The program is integrated in the website. So, readers can operate the program in the website (Attached section) by inputting the source codes i.e. optional process specifications and operating conditions.

\section{Specifications and operating conditions of an electrodialysis process}

Table 1 lists the standard process specifications and ED conditions. The process performances are computed by changing cell voltage $V_{\text {cell }}$ incrementally.

Int J Comput Softw Eng and the outlets of concentrating cells $C^{\prime \prime}{ }_{\text {out }}$, desalting ratio $a$, water recovery Re and current efficiency $\eta$.

Figure 9 is the limiting current density diagram in which the limiting current density $(I / S)_{\text {lim }}$ and $V_{\text {cell }}$ are plotted against $I / S$. The real limiting current density of the electrodialyzer $(I / S)_{\text {lim real }}$ is determined from the intersection between the $(I / S)_{\text {lim }}$ line and the $I / S=(I / S)_{\text {lim }}$ line as $(I / S)_{\text {lim,real }}=1.135 \mathrm{~A} / \mathrm{dm}^{2}$. From this point, the limiting cell voltage $\mathrm{V}_{\text {cell'lim }}=0.696 \mathrm{~V} /$ pair is presumed.

Figure 10 gives the current density distribution; $\mathrm{i}=\mathrm{a}_{1}+\mathrm{a}_{2}(\mathrm{x} / \mathrm{l})+$ $\mathrm{a}_{3}(\mathrm{x} / \mathrm{l})^{2}$. $\mathrm{i}$ is local current density at $x / l . x / l=0$ and $x / l=1$ correspond to respectively the inlet and the outlet of desalting and concentrating cell. $i$ becomes the average current density $I / S$ at $x / l=p$ which is shown by the point $(p, I / S)$ in the figure. 
Citation: Tanaka Y (2016) Saline Water Desalination with Single-pass Ion-exchange Membrane Electrodialysis - Computer Simulation. Int J Comput Softw Eng 1: 101. doi: http://dx.doi.org/10.15344/ijcse/2016/101

Page 8 of 10

\begin{tabular}{|c|c|}
\hline $\begin{array}{l}\text { Flow-pass thickness of desalting and } \\
\text { concentrating cells } a\end{array}$ & $0.05 \mathrm{~cm}$ \\
\hline $\begin{array}{l}\text { Flow-pass width of desalting and } \\
\text { concentrating cells } b\end{array}$ & $100 \mathrm{~cm}$ \\
\hline $\begin{array}{l}\text { Flow-pass length of desalting and } \\
\text { concentrating cells } l\end{array}$ & $100 \mathrm{~cm}$ \\
\hline Number of cell pairs $N$ & $300 \mathrm{~cm}$ \\
\hline Cell voltage $V_{\text {cell }}$ & $0.4 \mathrm{~V} /$ pairs \\
\hline $\begin{array}{l}\text { Salt concentration at the inlets of desalting } \\
\text { and concentrating cells } C_{\text {in }}^{\prime}=C^{\prime \prime}\end{array}$ & 2000 ppm \\
\hline $\begin{array}{l}\text { Linear velocity at the inlets of desalting cells } \\
u_{i n}^{\prime}\end{array}$ & $10 \mathrm{~cm} / \mathrm{s}$ \\
\hline $\begin{array}{l}\text { Linear velocity at the inlets of concentrating } \\
\text { cells } \mathrm{u}_{\text {in }}^{\prime}\end{array}$ & $1 \mathrm{~cm} / \mathrm{s}$ \\
\hline Temperature $T$ & $25^{\circ} \mathrm{C}$ \\
\hline $\begin{array}{l}\text { Standard deviation of a solution velocity } \\
\text { ratio in desalting cells }\end{array}$ & 0.1 \\
\hline Distance between spacer rods $\chi$ & $0.3 \mathrm{~cm}$ \\
\hline Crossing angle between spacer rods $\theta$ & $\pi / 3$ radian \\
\hline $\begin{array}{l}\text { Number of slots and ducts in desalting cells } \\
n^{\prime}\end{array}$ & 5 \\
\hline Width of slots in dessalting cells $w_{s}^{\prime}$ & $4 \mathrm{~cm}$ \\
\hline Length of slots in desalting cells $h_{s}^{\prime}$ & $4 \mathrm{~cm}$ \\
\hline Width of ducts in desalting cells $w_{d}^{\prime}$ & $4 \mathrm{~cm}$ \\
\hline Length of ducts in desalting cells $h_{d}^{\prime}$ & $4 \mathrm{~cm}$ \\
\hline $\begin{array}{l}\text { Number of slots and ducts in cencentrating } \\
\text { cells } n^{\prime \prime}\end{array}$ & 2 \\
\hline Width of slots in concentrating cells $w_{s}^{\prime \prime}$ & $2 \mathrm{~cm}$ \\
\hline Length of slots in concentrating cells $h_{s}^{\prime \prime}$ & $4 \mathrm{~cm}$ \\
\hline Width of ducts in concentrating cells $w_{d}^{\prime \prime}$ & $2 \mathrm{~cm}$ \\
\hline Length of ducts in concentrating cells $h_{d}^{\prime \prime}$ & $2 \mathrm{~cm}$ \\
\hline
\end{tabular}

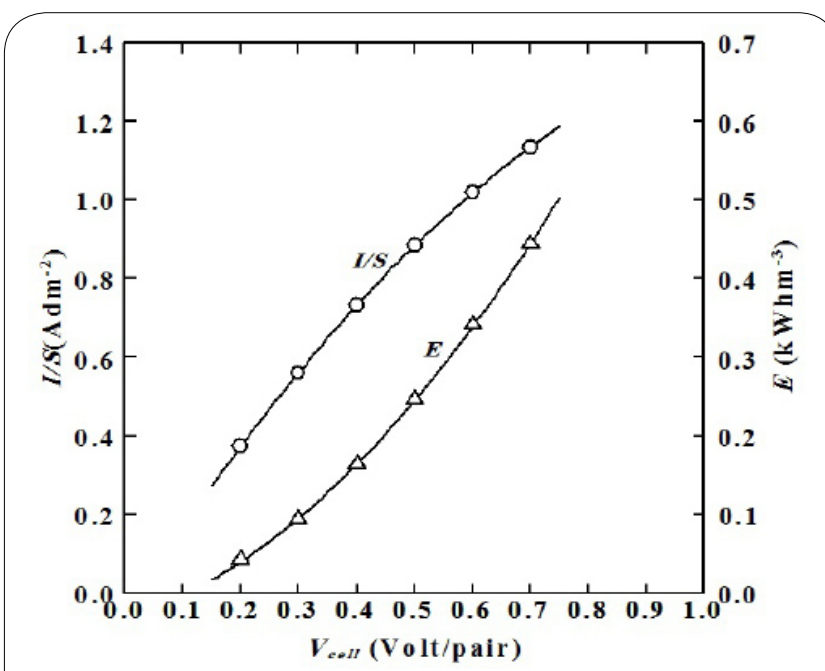

Figure 7: Current density and energy consumption.
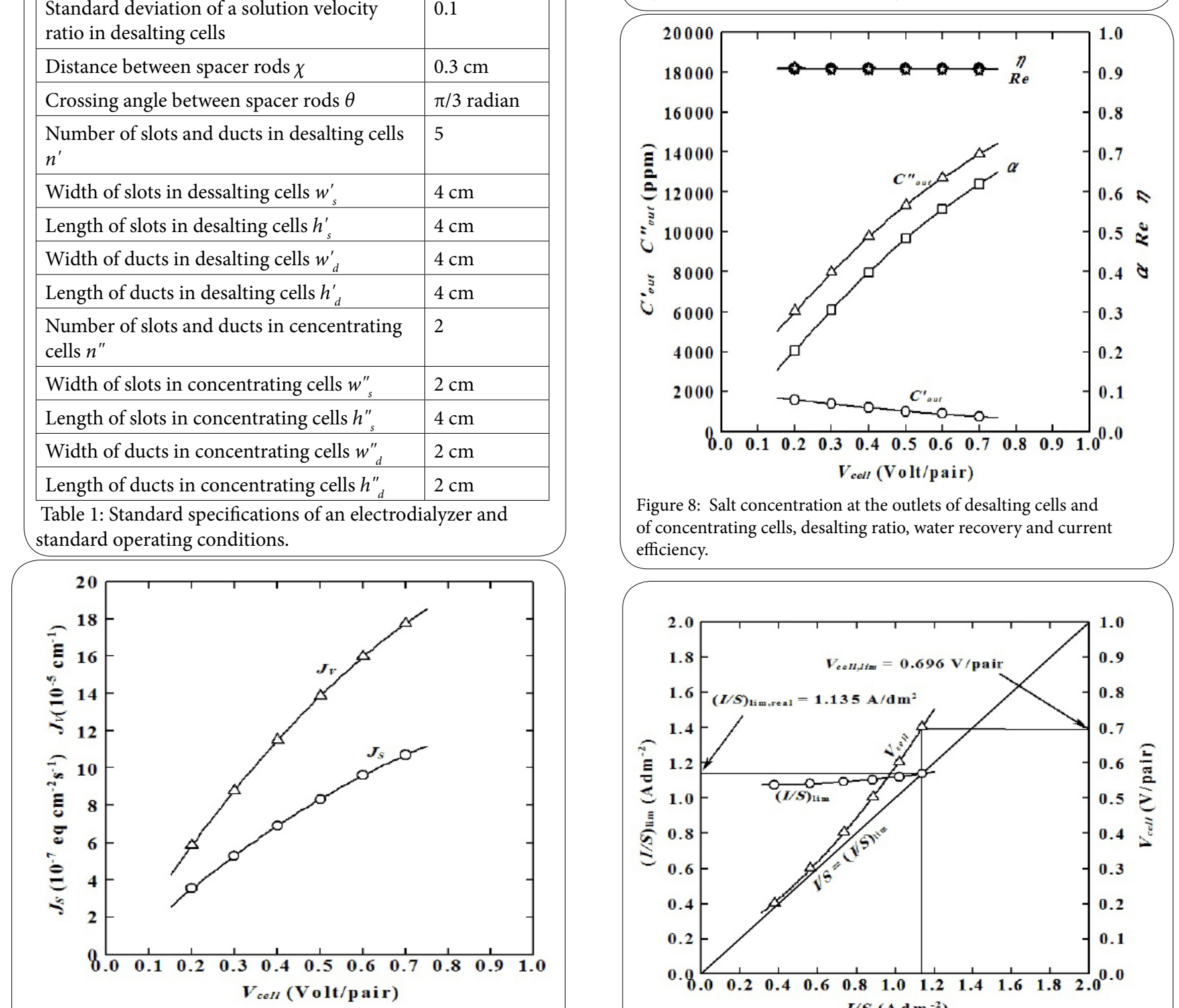

Figure 6: Ion flux and solution flux across a membrane pair.

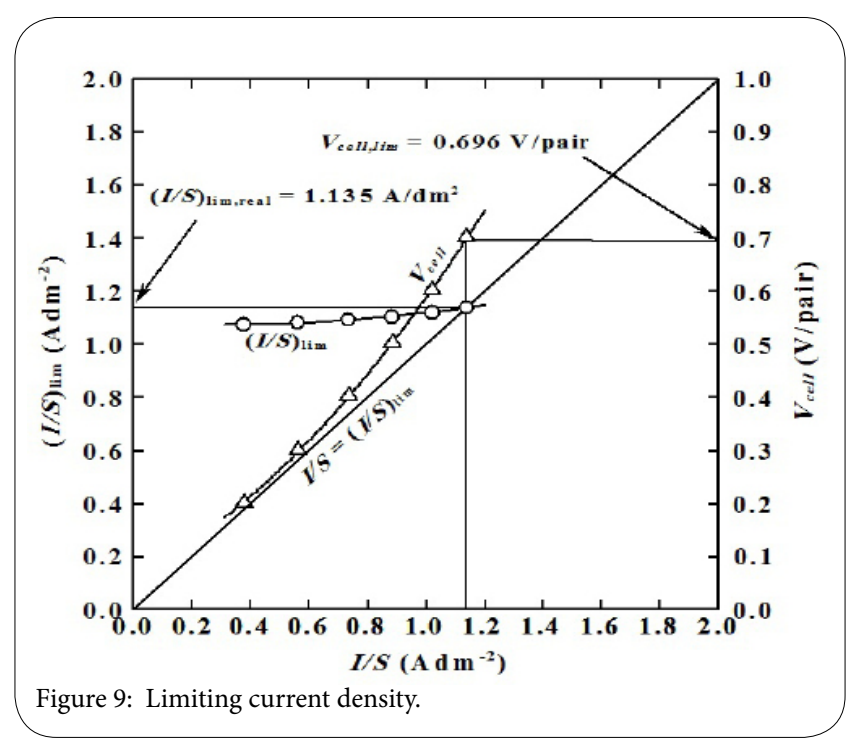


Citation: Tanaka Y (2016) Saline Water Desalination with Single-pass Ion-exchange Membrane Electrodialysis - Computer Simulation. Int J Comput Softw Eng 1: 101. doi: http://dx.doi.org/10.15344/ijcse/2016/101

Page 9 of 10

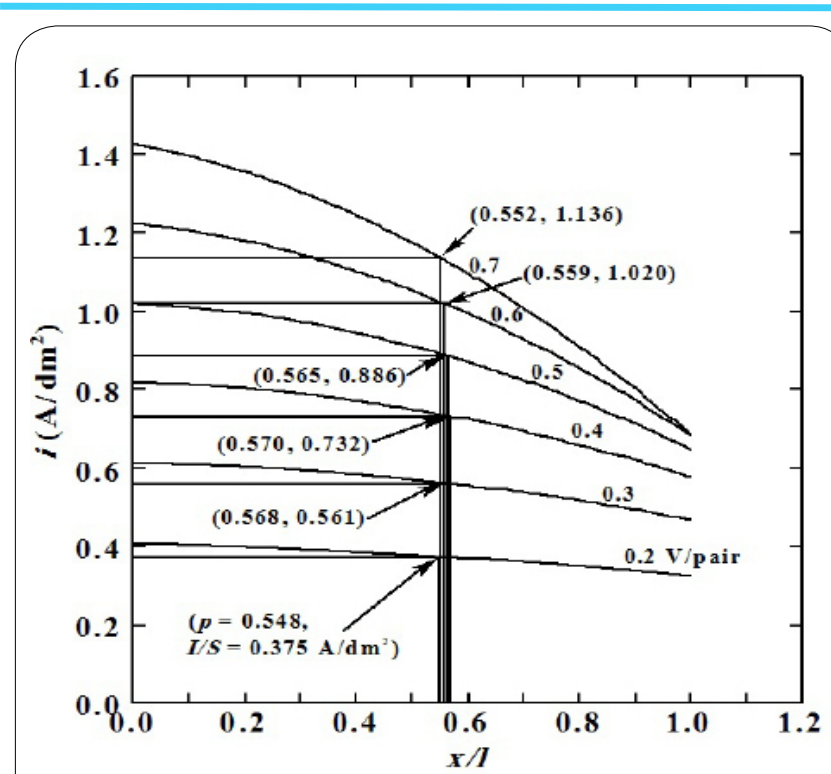

Figure 10: Current density distribution.

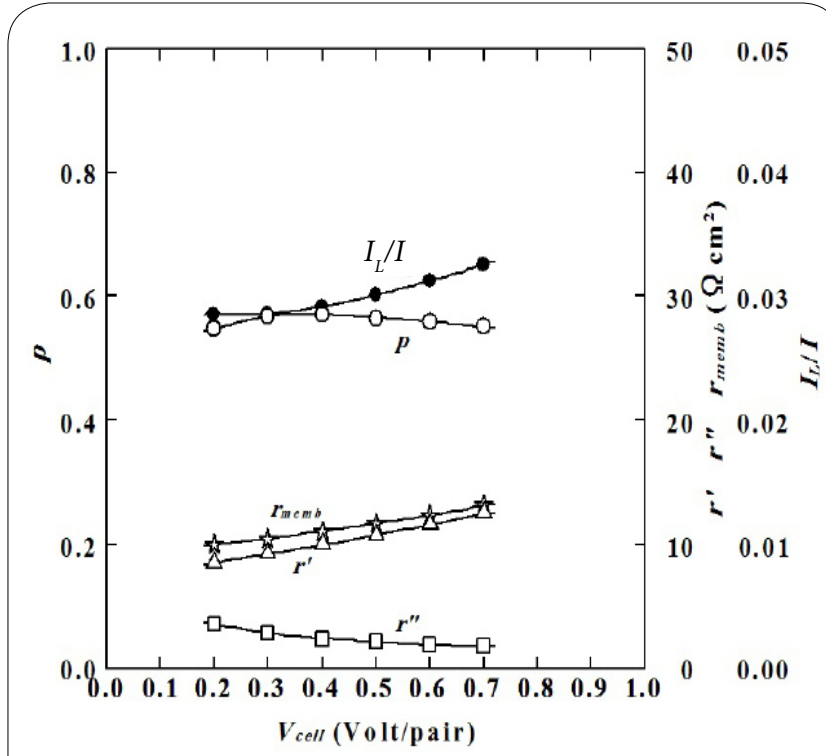

Figure 11: p, r', r", rmemb and $I_{L} / I$.

Figure 11 shows $V_{\text {cell }}$ versus $p, r^{\prime}, r^{\prime \prime}, r_{\text {memb }}$ and $I_{L} / I$. Here, $r^{\prime}, r^{\prime \prime}$ and $r_{\text {memb }}$ are respectively the electric resistance of the solution in the desalting cell, in the concentrating cell and the direct electric resistance of a membrane pair at $x / l=p . I_{L} / I$ is the electric current leakage. With the increase of $V_{\text {cell }} r$ "' is decreased, however, $r^{\prime}, r_{m e m b}$ and $I_{L} / I$ are increased. When $V_{\text {cell }}$ is decreased toward zero, $p$ is seen to be decreased after passing through the maximum value.

Figure 12 shows total pressure drop in the desalting side $\Delta P_{\text {total }}^{\prime}$ and in the concentrating side $\Delta P_{\text {total }}$, and pressure drop in the electric current passing portion in the desalting cell $\Delta P_{\text {cell }}^{\prime}$ and in the concentrating cell $\Delta P^{\prime \prime}{ }_{\text {cell }}$. The pressure drop in the slot in the desalting cell and in the concentrating cell $\Delta P_{\text {slot }}$ is equivalent to the total pressure drop at the inlet and outlet; $\Delta P_{\text {slot }}^{\text {slot }}=\Delta P_{\text {slot,inlet }}+\Delta P_{\text {slotoutlet }}$ and it is calculated from $P_{\text {slot }}=\Delta P_{\text {total }}-\Delta P_{\text {cell }}$.

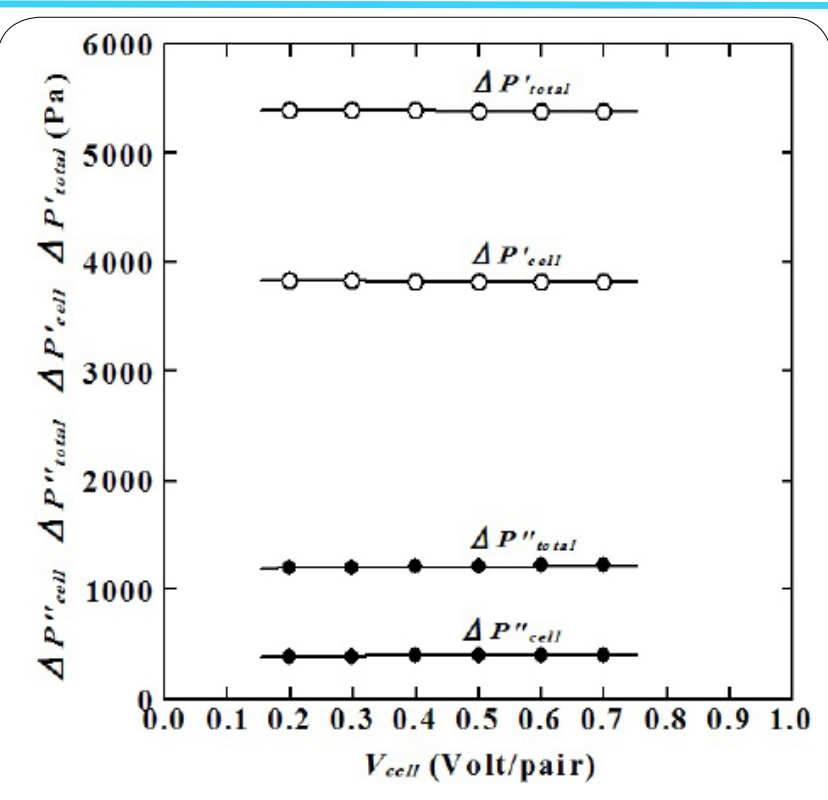

Figure 12: Pressure difference.

\section{Attached Section}

\section{Computing steps in the program in the website}

\section{A1 Website}

The website is established based on the stand alone ED program. This section describes "Constant voltage single-pass (continuous) program" integrated in the website.

\section{A2 Steps in the program computation}

The program is written in the Excel spread sheet, and it consists of the following 11 steps.

Step 1 Fundamental specifications of an electrodialyzer and operating conditions

Step 2 Fundamental operating conditions of an electrodialyzer

Step 3 Solution electric resistance and salt activity coefficient in concentrating cells

Step 4 Solution electric resistance and salt activity coefficient at the inlets of desalting cells

Step 5 Computation at $V_{\text {in }}=V_{\text {out }}$

Step $6 i_{i n}, i_{\text {out }}$ ohmic voltage, membrane potential, cell voltage, energy consumption

Step 7 Computation at $V_{i n}=V_{p}$

Step $8 p, \zeta_{\text {in }}, \zeta_{\text {out }}, a_{1}, a_{2}$ and $a_{3}$

Step 9 Solution viscosity and pressure difference in desalting cells and concentrating cells

Step 10 Electric current leakages

Step 11 Limiting current density

\section{A3 Remarks in the program computation}

(1) Calculations in the decision points are marked with red. Inputs are marked with purple. Important values are marked with blue.

(2) Readers can operate the program by inputting the optional input (purple) and carrying out the trial-and-error calculations at the decision points (red) as follows (cf. Figure 4 and Section 6). 
Citation: Tanaka Y (2016) Saline Water Desalination with Single-pass Ion-exchange Membrane Electrodialysis - Computer Simulation. Int J Comput Softw Eng 1: 101. doi: http://dx.doi.org/10.15344/ijcse/2016/101

Page 10 of 10

Decision point 1

Control key $1 ; I^{*}$

Adjust I ${ }^{*} / S$ to realize $V_{\text {cellinput }}=V_{\text {cell }}$

Decision point 2

Control key 2; $C^{\prime}{ }^{*}{ }^{*}, C^{\prime \prime}{ }^{*}{ }^{*}$

Adjust $C_{p}^{* *}$ and $C_{p}^{\prime \prime *}$ to realize $C_{p}^{*}=C_{p}^{\prime}$ and $C_{p}^{\prime *}=C_{p}^{\prime \prime}$

Decision point 3

Control key 3; $p^{*}$

Adjust $p^{*}$ to realize $\zeta_{\text {inout }}=\zeta_{\text {inp }}$

Decision point 4

Control key $4 ; I^{\#^{*}}$

Adjust $I^{* *}$ to realize $I^{\sharp *}\left(1-I_{L} / I^{* *}\right)=I$

Limiting current density

Control key; $C_{\text {out }}^{\prime \prime *}$

Adjust $C_{\text {out }}^{\prime *^{*}}$ to realize $Z_{1}=Z_{2}$

(3) Steps 10 and 11 are computed after the computations from Step 1 to Step 9 are finished. All computations are completed within about 10 minutes.

(4) Summary is supplied at the end of the spread sheet for printing.

\section{Competing Interests}

The author declare that he has no competing interests.

\section{References}

1. Belfort G, Daly JA (1970) Optimization of an electrodialysis plant Desalination 8: 153-166.

2. Avriel M, Zelighter $N$ (1972) A computer method for engineering and economic evaluation of electrodialysis plant. Desalinaeion 10: 113-146.

3. Lee HJ, Sarfert F, Strathmann H, Moon SH (2002) Designing of an electrodialysis desalination plant. Desalination 142: 267-285.

4. Moon P, Sandi G, Stevens D, Kizilel R (2004) Computational modeling of ionic transport in continuous and batch electrodialysis. Sep Sci Technol 29: 2531-2555.

5. Fidaleo M, Moresi M (2005) Optimal strategy to model the electrodialytic recovery of a strong electrolyte. J Membr Sci 260: 90-111.

6. Sadrzadeh M, Kaviani A, Mohammadi T (2007) Methematical modeling of desalination by electrodialysis. Desalination 206: 534-549.

7. Nikonenko VV, Pismenskaya ND, Itoshin AG, Zabolotsky VI, Shudrenko AA (2008) Description of mass transfer characteristics of ED and ED apparatus by using the similarity theory and computation method. Chem Eng Process 47: 1118-1127.

8. Brauns E, De Wide W, Van den Bosch B, Lens P, Pinoy L, Empsten M (2009) On the experimental verification of an electrodialysis simulation model for optimal stack configuration design through solver software. Desalination 249: 1030-1038.

9. Tanaka Y (2014) Development of a computer simulation program of feed-and-bleed ion-exchange membrane electrodialysis for saline water desalination. Desalination 342: 126-138.

10. Tanaka $Y$ (2013) Development of a computer simulation program of batch ion-exchange membrane electrodialysis. Desalination 320: 118-133.

11. Tanaka Y (2012) lon-exchange membrane electrodialysis program and its application to multi-stage continuous saline water desalination Desalination 301: 10-25.
12. Tanaka Y (2015) Ion Exchange Membranes. Fundamentals and Applications 2nd edition. Elsevier, Amsterdam, pp. 295-322.

13. Tanaka $Y(2006)$ Irreversible thermodynamics and overall mass transport in ion-exchange membrane electrodialysis. J Membr Sci 281: 517-531.

14. Tanaka $Y(2011 a)$ lon-exchange membrane electrodialysis of saline water and its numerical analysis. Ind Eng Chem Res 50: 10765-10777.

15. Tanaka Y (2011b) lon-exchange membrane electrodialysis for saline wate desalination and its application to seawater concentration. Ind Eng Chem Res 50: 7494-7503.

16. Tanaka $Y$, Ehara $R$, Itoi $S$, Goto $T$ (2003) lon-exchange membrane salt production using brine discharged from a reverse osmosis seawater desalination plant. J Membr Sci 222: 71-86.

17. Tanaka $Y(2000)$ Current density distribution and limiting current density in ion-exchange membrane electrodialysis. J Membr Sci 173: 179-190.

18. Tanaka $Y(2002)$ Current density distribution, limiting current density and saturation current density in an ion-exchange membrane electrodialyzer. $J$ Membr Sci 210: 65-75.

19. Zimmerer CC, Kottke $V$ (1996) Effects of spacer geometry on pressure drop, mass transfer, mixing behavior, and residence time distribution. Desalination 104: 129-134.

20. Tsiakis P, Papageorgiou LG (2005) Optimal design of an electrodialysis brackish water desalination plant. Desalination 173: 173-186.

21. Wilson JR (1960) Demineralization by Electrodialysis. Buther-worths Scientific Publication, London, pp. 265-274. 